\title{
Physique Characteristics of Ethnic Archers Based on R-cluster Matrix Yunfeng Wang ${ }^{1}$, Yinan $\mathrm{Ma}^{1}$ \\ ${ }^{1}$ Sports Institute, Qiongzhou University, Sanya, 572022 ,China \\ ${ }^{2}$ Yili Normal University, Yining, 835000, China \\ yunfengwang2011@yeah.net
}

Keywords: Xibo ethnic archers; Physique characteristics; R cluster matrix analysis

\begin{abstract}
Object: the $\mathrm{R}$ cluster matrix analysis is used in this research which to explore the correlation of body shape, body composition, physical function and body function of male Xibo ethnic archers in China, and then discuss the differences of physical characteristics among Xibo ethnic archers and other athletes.Method: we used the R cluster matrix analysis and Hierarchical cluster diagram to build the model of physique index of male Xibo ethnic archers. Results: (1) The pyhsical characteristics of Xibo ethnic archers divided into three groups which are LBM/weight, weight and vital capacity, body fat ratio and VO2max; (2) According to T test, some indices such as body fat ratio are smiliar to the athletes of football and judo, but vital capacity and VO2max are lower than them. Conclusion: the body shape and pyhsical function of Xibo ethnic archers relate to obvious R cluster matrix, and the excellent physique characteristics need the advantage of strength endurance which no less than sports which need body contact, such as football, judo.
\end{abstract}

\section{Introduction}

Since 1973, there are many excellent Xibo ethnic archers who had won the gold metals in many international and national competitions, and the archery school trained 48 national level of athletes, so there are many researches for archers, such as psychological characteristics,body function and training, but there's no research of the R cluster matrix analysis of physique characteristics of male Xibo ethnic archers in China, so this research is to explore the relatives of body shape, body composition, physical and body function of male Xibo ethnic archer in China, and then discuss the differences of physical characteristics among Xibo ethnic archers and other athletes, which may provide the theoretical basis of the selection of Xibo ethnic archers.

\section{Object and Method of Research}

\section{Research Object}

5 male Xibo ethnic archers who had excellent results in national competitions, and 15-17years old.

\section{Research Method \\ Test of physique index}

(1)automatic height and weight measurement instrument

measuring range:0 -999.9s sharpness of separation:0.1s; accuracy of measurement: $0.1 \% \mathrm{FS}$

(2)vital capacity measurement instrument

measuring range: 0 -9999ML sharpness of separation: 1s;accuracy of measurement: $0.5 \% \mathrm{FS}$

(3) test of LCSPFT

(4)test of hemoglobin: HiCN

(5)Riva-Rocci sphygmomanometerfor the test of blood pressure

(6)test model of step index: platform: $45 \mathrm{~cm}$.

Step index $=$ movement time $(\mathrm{s}) \times 100 /[2 \times(1$ to 1.5 miutes +2 to 2.5 minutes +3 to 3.5 minutes'heartbeats)]

(7)the calculation of $\mathrm{VO} 2 \mathrm{max}$ 
let the step index $(\mathrm{x})$ into regression equation for conjecture $\mathrm{VO} 2 \mathrm{max}(\mathrm{Y})$

$\mathrm{Y}(\mathrm{ml} / \mathrm{min})=13.25 \mathrm{X}+1740.86$

\section{Test of BROZEK}

(1)testing part: A. skin fold of muscle belly oftriceps brachii(mm); B.skin fold under right scapula(mm).

(2)calculate the index of body composition.

(1) body density(D) $=1.0973-0.00146 \mathrm{x}, \mathrm{X}$ is skin fold thickness of shoulder blade and arm.

(2) body fat $(\mathrm{F} \%)=(4.57 / \mathrm{D}-4.142) \times 100$

(3) fat mass $=$ weight $(\mathrm{Kg}) \times \mathrm{F} \%$

(4) lean body mass $(\mathrm{LBM})=$ weight $(\mathrm{kg})$ - fat mass $(\mathrm{kg})$

(5) $\mathrm{LBM} /$ weight $\times 100$

(6) $\mathrm{LBM} /$ height $\times 100$

(7) fat mass / height $\times 100$

\section{LCSPFT test}

(1)100-meter running(s)

(2)1500-meter running (s)

(3)standing long jump (cm)

(4)throwing the shot backword ( $\mathrm{m}$ )

Process of $R$ cluster matrix

Cluster method of $R$ ij correlation coefficient

$\mathrm{Rij}=\mathrm{Lij} / \sqrt{L i i \times L i j}$ is the formula of R cluster matrix

Rij indicate the correlation coefficient between the two index

$\mathrm{i}$ indicates variable quantity if a index; $\mathrm{j}$ indicates another variable quantity which relate with I;

Lii indicates squared residuals of $\mathrm{i}$; Ljj indicates squared residuals of $\mathrm{j}$

Lij indicates the deviation of product

The correlation coefficient with mathematical derivation

(1)Calculate the two index between 1 and 2, 1 expressed as $x(i), 2$ expressed as $y(j)$

(2)Calculate the correlation coefficient ( $\mathrm{r}$ ) of $\mathrm{x}$ and $\mathrm{y}$

(3)Calculate $\sum \mathrm{y}, \sum \mathrm{y}^{2}$.

(4) $\mathrm{Lxx}(\mathrm{Lii})=\sum(\mathrm{X}-\bar{x})^{2}$ it is the squared residual of $\mathrm{x}$ and $\mathrm{y}$

(5) $\mathrm{L}_{\mathrm{yy}}(\mathrm{Ljj})=\sum(\mathrm{Y}-\bar{y})^{2}$ it is the squared residual of $\mathrm{y}$

(6) $\mathrm{Lxy}(\mathrm{Lij})=\sum(\mathrm{Y}-\bar{x})(\mathrm{Y}-\bar{y})$ it is the squared residual of $\mathrm{x}$ and $\mathrm{y}$

$\mathrm{r}=\mathrm{Lxy} / \sqrt{\operatorname{Lxx} L y y}$, and other correlation coefficients of index are same

1 and $3 ; 1$ and $4 ; 1$ and 5

2 and $3 ; 2$ and $4 ; 2$ and 5:

Finally, draw a hierarchical diagram.

\section{statistics}

The statistics of cluster matrix of derived indicators

Software of SPSS16.0 is used to do R cluster matrix analysis and calculate the correlation coefficient matrix of relative index, then describe the male Xibo ethnic archers

The statistics description of physical characteristics

SPSS16.0 is used to do independent samples T test and expressed as 


\section{Results}

The results of physical characteristics index

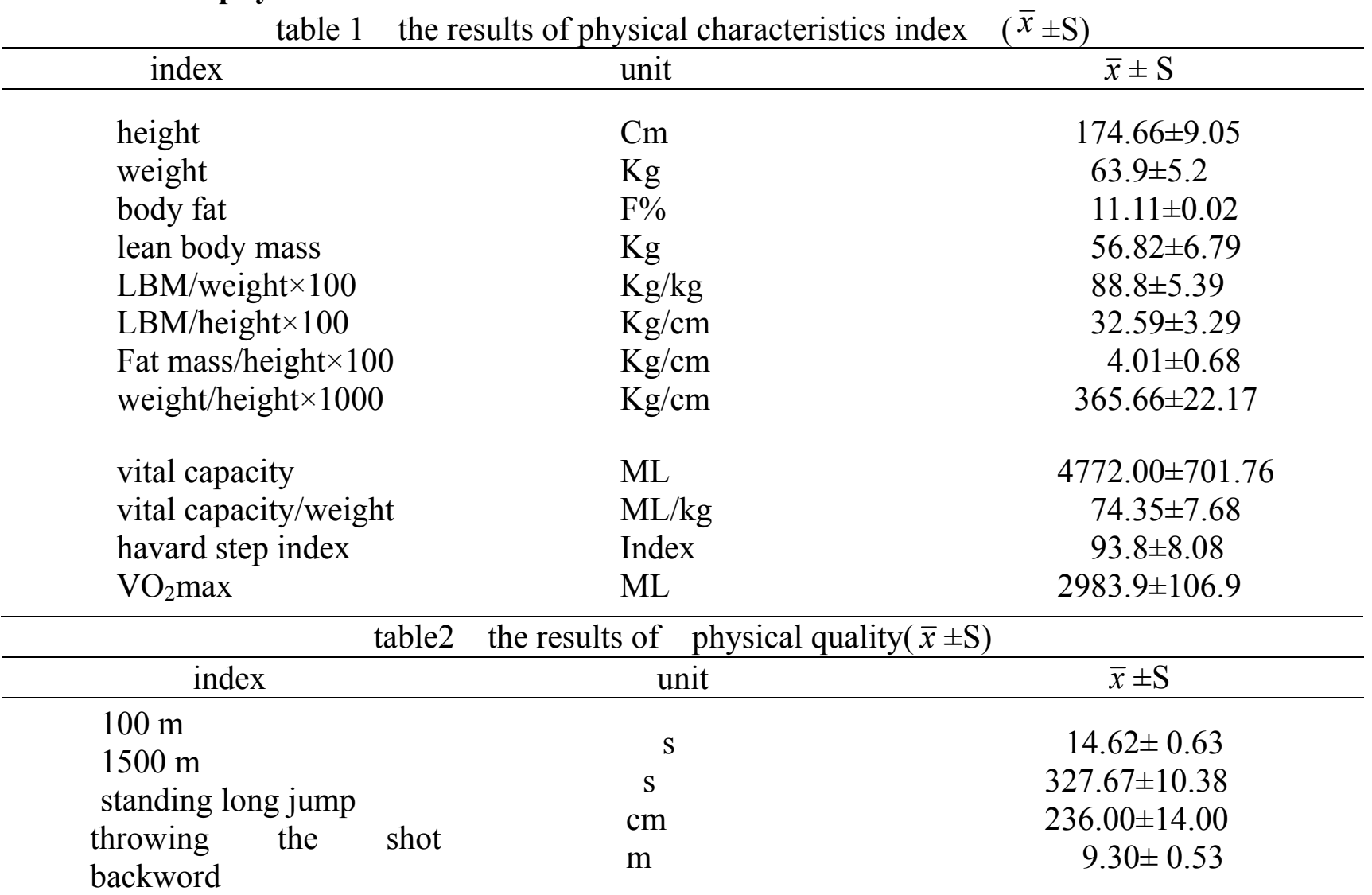

Table 1 and table 2 are the physical characteristics and physical quality of male Xibo ethnic archers. The correlation coefficient matrix of male Xibo ethnic archers

Table 3 relative index matrix of male Xibo ethnic archers

\begin{tabular}{|c|c|c|c|c|c|c|c|c|}
\hline & relative index & 1 & 2 & 3 & 4 & 5 & 6 & 7 \\
\hline 1 & LBM/weight & 1.000 & -.997 & -.939 & .383 & -.051 & .558 & .090 \\
\hline 2 & body fat & & 1.000 & .926 & -.397 & .015 & -.507 & -.109 \\
\hline 3 & fat mass/height & & & 1.000 & -.050 & .103 & -.565 & .253 \\
\hline 4 & LBM/height & & & & 1.000 & .014 & .246 & .953 \\
\hline 5 & $\mathrm{VO}_{2} \max$ & & & & & 1.000 & -.025 & .052 \\
\hline 6 & Vital capacity/weight & & & & & & 1.000 & .039 \\
\hline 7 & weight/height & & & & & & & 1.000 \\
\hline
\end{tabular}

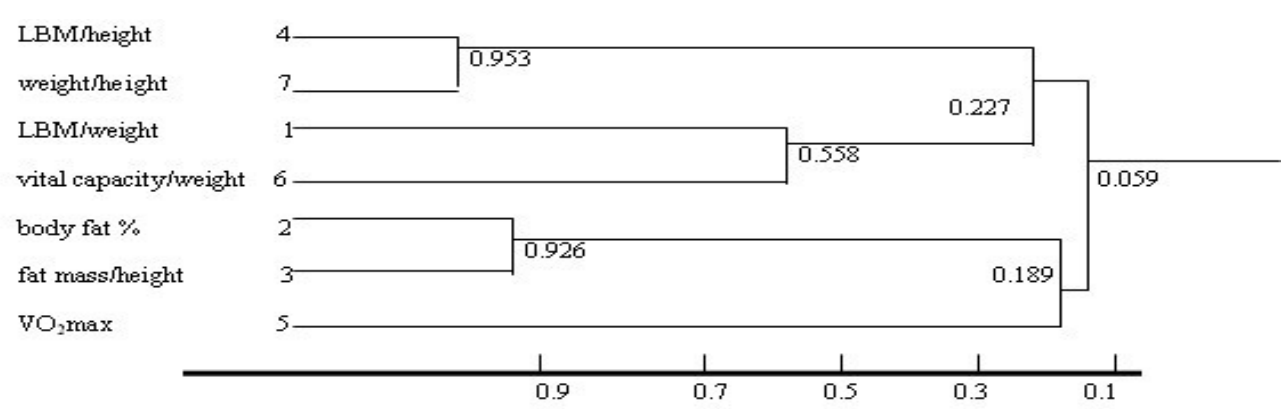

fig. 1 clustering diagram of relative index matrix of male Xibo ethnic archers

According to table 3, and fig.1, body shape and pyhsical function of Xibo ethnic archers have obvious R cluster matrix and the result of derivative index divided into three groups, they are (1) 
LBM/weight, weight/height;(2) LBM/weight, vital capacity/weight;(3) body fat \% , fat mass/height, $\mathrm{VO}_{2}$. So the characteristics of relative index may plays an important role in selection of male Xibo ethnic archers.

\section{Analysis and discussion}

Results of body composition among athletes of football players,judokas, and archers table 4 the result of body composition among football player,judoka,and archer

\begin{tabular}{lrrrrrr}
\hline $\begin{array}{c}\text { Item } \\
\text { mass } / \text { height }\end{array}$ & $\mathrm{n}$ & body fat $\%$ & lean body mass & \multicolumn{2}{l}{ LBM/weight } & LBM/height fat \\
\hline football & 18 & $12.98 \pm 4.70$ & $51.84 \pm 4.64$ & $87.00 \pm 2.00$ & $29.94 \pm 2.14$ & $4.38 \pm 0.96$ \\
judo & 7 & $10.89 \pm 1.12$ & $63.24 \pm 7.22$ & $89.00 \pm 1.40$ & $36.00 \pm 2.20$ & $4.00 \pm 0.80$ \\
archery & 5 & $11.11 \pm 0.02$ & $56.82 \pm 6.79$ & $88.80 \pm 5.39$ & $32.59 \pm 3.29$ & $4.00 \pm 0.68$ \\
\hline
\end{tabular}

Table 5 T test of body composition

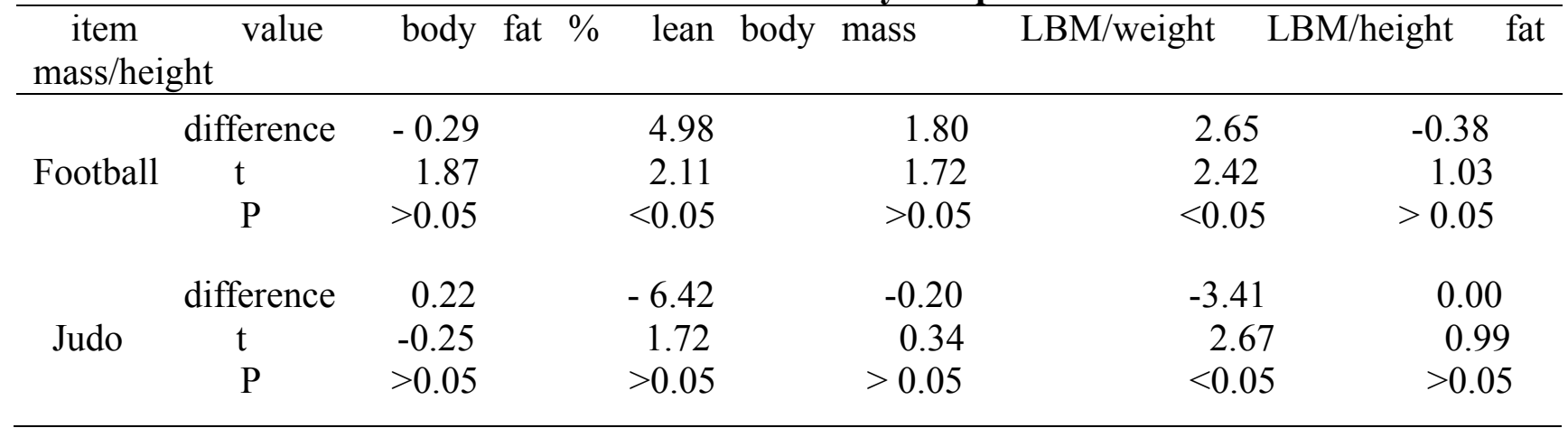

According to table 4 and table 5, the lean body mass of archers are hihger than football players, $\mathrm{P}<0.05$, and the index of LBM/weight are also hgiher than football players, but lower than judokas, this shows that the male archers need the training of strength endurance, and the training standard should no less than the sports which need body contact and strength endurance.

Results of derived physiological index among athletes of football players, judukas and archers

Table6 results of derived physiological index among athletes of football players, judokas and archers

\begin{tabular}{|c|c|c|c|c|}
\hline item & $\mathrm{n}$ & jital capacity/weight & havard step index & $\mathrm{VO}_{2} \max$ \\
\hline \multicolumn{5}{|l|}{ footba } \\
\hline 11 & 18 & $79.36 \pm 6.23$ & $109.82 \pm 12.58$ & $3195.99 \pm 166.89$ \\
\hline judo & 7 & $81.54 \pm 7.69$ & $112.05 \pm 11.26$ & $3225.55 \pm 149.41$ \\
\hline archer & 5 & $74.35 \pm 7.68$ & $93.80 \pm 8.08$ & $2983.90 \pm 106.90$ \\
\hline \multicolumn{5}{|l|}{$\mathrm{y}$} \\
\hline \multicolumn{5}{|c|}{ Table $7 \quad$ T test of derived physiological index } \\
\hline item & value & vital capacity/weight & havard step index & $\mathrm{VO}_{2} \max$ \\
\hline \multirow{3}{*}{ football } & difference & -5.01 & -16.02 & -212.00 \\
\hline & $\mathrm{t}$ & 1.34 & 3.43 & 3.42 \\
\hline & $\mathrm{P}$ & $<0.05$ & $<0.01$ & $<0.01$ \\
\hline \multirow{3}{*}{ Judo } & difference & -7.19 & -18.25 & -241.65 \\
\hline & $\mathrm{t}$ & 0.99 & 3.48 & 3.57 \\
\hline & $\mathrm{P}$ & $<0.05$ & $<0.01$ & $<0.01$ \\
\hline
\end{tabular}

According to table 6and table 7, vital capacity/weight of archers are lower than football players and judokas, $\mathrm{P}<0.05$, havard step index and $\mathrm{VO}_{2}$ max are extremely lower than football players and 
judokas, $\mathrm{P}<0.01$, this shows that the request of archerscardiopulmonary function of archers are lower.

Results of physical quality among athletes of football players,judokas and archers

Table 8 results of physical quality among athletes of football players, judokas and archers

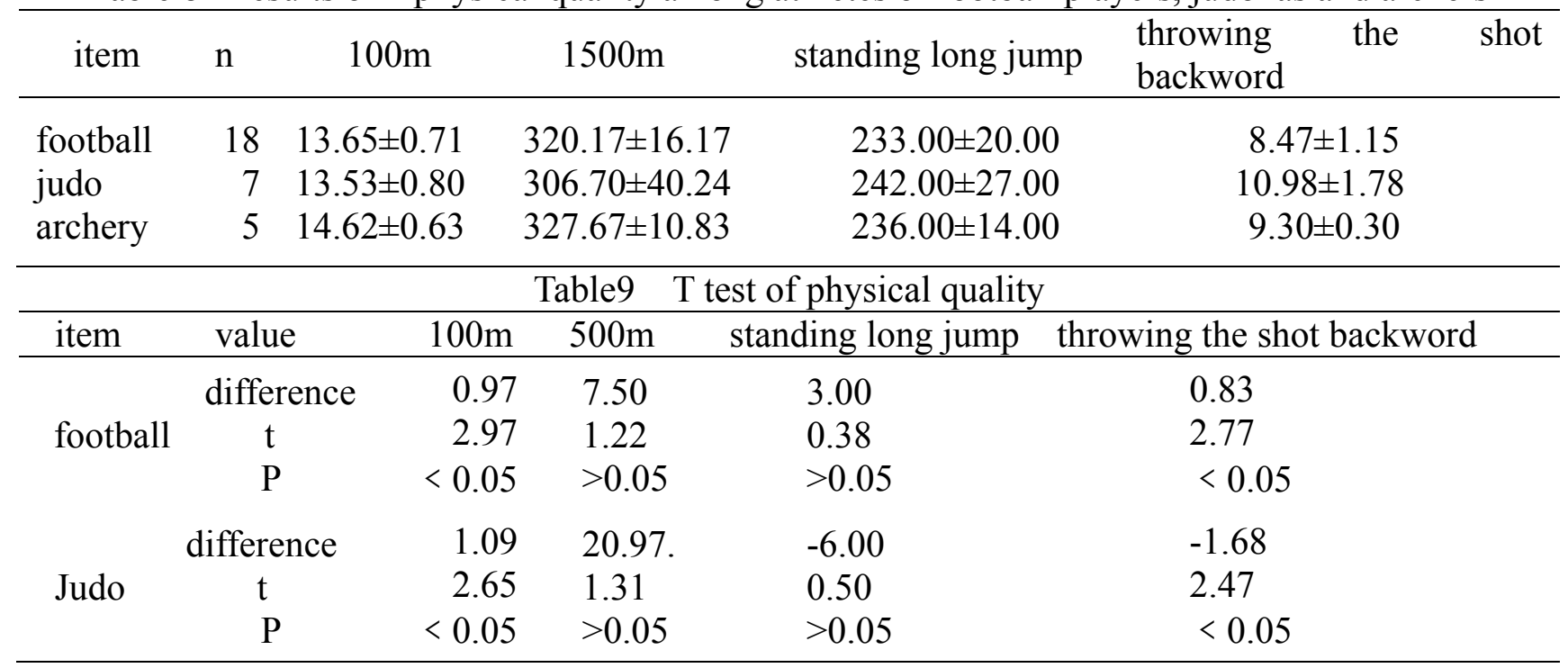

According to table 8 and table 9, the level of 100-meter running of archers is lower than football players and judokas, $\mathrm{P}<0.05$, the speed of 1500 -meter running is also lower, but there's no significant difference, the level of standing long jump of archers is higher than football palyers, but lower than judokas, there's also no significant difference. The level of throwing the shot backword of archers is higher than football players, $\mathrm{P}<0.05$, but lower than judokas, this shows that except speed quality, the force and endurance abilities of archers are smiliar to the sports which need body contact and strength endurance, espically the waist muscle strength, the upper and lower body strength are even better than footplayers and judokas.

\section{Conclusion}

To sum up, the body shape and pyhsical function of Xibo ethnic archers have obvious $\mathrm{R}$ cluster matrix, and the physique characteristics need excellent strength endurance, and the male archers need the training of strength endurance, and the training standard should no less than the sports that need body contact and strength endurance. All those may provide the theoretical basis of the selection of Xibo ethnic archers.

\section{References}

[1] Liu QS. The archery's culture of Xibo ethnic in Xinjiang [J] china science and technology information,2006,5(23):157-158

[2] He Y,Wang T, Shi Y. Research on Brain Function Feature of Elite Archery Athlete before Major Competition [J]. china sport science and technology and , 2009,45 (1) : 83-93

[3] Zhou WA,He WG. research on characteristics of brain neurobiology of Elite Archery Athlete in china[J]. Chinese Journal of Sports Medicine,,2007,26 (6) :720-722.

[4] Feng XD, Tian YL, Fu T. A study on stamina training of Chinese high-level archers [J]. Journal of Wuhan Institute of Physical Education, 2001,35 (3) : 57-60 